DOI: $10.17957 / \mathrm{IJAB} / 15.1901$

http://www.fspublishers.org

\title{
Modified Atmosphere as an Alternative Measure for Controlling of Sitophilus oryzae Reared on Different Stored Grains
}

\author{
Muhammad Mohsan', Zahid Mahmood Sarwar², Zafar Hussain², Muhammad Shahbaz Asghar², Muhammad Adnan \\ Badar $^{3}$ and Muhammad Rafique Khan ${ }^{4}$ \\ ${ }^{1}$ Department of Entomology, University of Agriculture Faisalabad, Punjab, Pakistan \\ ${ }^{2}$ Department of Entomology, FAST Bahauddin Zakariya University Multan, Pakistan \\ ${ }^{3}$ Department of Horticulture, Pir Mehr Ali Shah Arid Agriculture University Rawalpindi, Pakistan \\ ${ }^{4}$ Department of Zoology, faculty of Basic and Applied Sciences, University of Poonch Rawalakot, Azad Jammu \& \\ Kashmir, Pakistan \\ *For correspondence: zmsarwar@bzu.edu.pk \\ Received 07 September 2021; Accepted 28 December 2021; Published 30 January 2022
}

\begin{abstract}
Protection of grains and their products from insect pests remained a big constraint in the way of food security. Current study evaluated the effective exposure time to kill the Sitophilus oryzae (L.), reared on two different diets viz., wheat and maize under six Carbon dioxide $\left(\mathrm{CO}_{2}\right)$ concentrations. Modified atmospheres (MA) contained 25, 30, 35, 40, 45 and 50\% $\mathrm{CO}_{2}$ by volume at ambient temperature, respectively. Twenty $S$. oryzae adults, along with a $20 \mathrm{~g}$ diet, were released in each airtight exposure chamber $\left(150 \mathrm{~mL}\right.$ capacity). A measured quantity of $\mathrm{CO}_{2}$ gas $(99.9 \%)$ was released in exposure chamber by the injection syringe from gas cylinder. Mortality data were recorded after 24, 48, 72, 96 and 120 h. The mortality rates varied between the insect cultures reared on maize and wheat diets. S. oryzae, reared on a wheat diet, showed higher mortality after exposure to all $\mathrm{CO}_{2}$ concentrations as compared to the insect culture reared on the maize diet. At $45 \% \mathrm{CO}_{2}$ concentration, maximum mortality (100\%) was observed after $120 \mathrm{~h}$ in case of maize reared insects and (100\%) after $96 \mathrm{~h}$ in case of wheat reared $S$. oryzae. The results revealed that Carbon dioxide, as an eco-friendly approach, may be used as the best alternative method to minimize the pest infestation in stored products to avoid insecticide resistance development in stored grain insect pests. The Carbon dioxide is not included in the category of toxic gases and has no detrimental or residual effect in the stored grains. (C) 2022 Friends Science Publishers
\end{abstract}

Keywords: Carbon dioxide; Modified atmosphere; Sitophilus oryzae; Mortality response

\section{Introduction}

Stored grains are a very important source of calories and proteins for human throughout the world but arthropod pests play a negative role by disturbing the supply of these grains. Insect pests damaged grains have low marketing value because of less nutritive quality and bad taste (AlonsoAmelot and Avila-Núñez 2011). Insect pests of stored grains damage stored products by causing $5-10 \%$ losses globally while $10-40 \%$ losses in developing countries (Weaver and Petroff 2005), including Pakistan (Ahmad 1984). Human survival mainly depends upon the wheat crop because it contributes major part in the economy of any country (Yu et al. 2017). Maize is also main and important food of the world (Kennett et al. 2020). In agriculture, grains constitute the major component of food items. Grains like rice, wheat and maize cover $43 \%$ food calories and $87 \%$ grain production, globally. To fulfill the food requirement of $42 \%$ population of the world, we depend upon maize (Khan 2018).
Unfortunately, these grains are attacked by numerous kinds of insect pests during storage conditions. Coleopteron and Lepidopteron insect pests are the most significant insect pests causing huge destruction to grains in the field and storage (Emana and Tsedeke 1999). The coleopteron insects attacking stored grains during storage are four types' beetles. Among these beetles, rice weevil (Sitophilus oryzae L.) is widely distributed globally. It is very destructive primary pest of stored grain, mostly prefer soft grain varieties (Pathak and Jha 2003; Padmasri et al. 2017).

Insect pests of stored grains and their products have been controlled by the application of insecticides. Due to repetition of insecticides application, insect pests have developed insecticide resistance against these insecticides (Wallbank and Collins 2003). Besides the development of insecticide resistance in insects, some of these chemicals are also banned due to hazardous effects on human health (Isman 2006) and the environment (Haines 1995). Resistance and harmfulness issues of synthetic insecticides

To cite this paper: Mohsan M, ZM Sarwar, Z Hussain, MS Asghar, MA Badar, MR Khan (2022). Modified atmosphere as an alternative measure for controlling of Sitophilus oryzae (L.) reared on different stored grains. Intl J Agric Biol 27:77-82 
have brought about the needs of discovering more viable and healthier alternatives.

It is in high demand of the food industry to control arthropod pests through different eco-friendly control methods. These techniques are also promoted by the government through financial support and legislation because the food market needs increased demand for organic grains. Therefore, different non-chemical and ecofriendly methods have been adopted. Among these, the modified atmosphere (MA) approach is suitable for the control of stored product insect pests (Adler et al. 2000; Navarro 2006). To overcome the infestation of stored commodities pests, the modified atmosphere technique is considered an environmentally safe method. Montreal protocol, an international agreement, suggested the scientists develop different alternatives tore place methyl bromide and similar products due to health and environmental hazards (Fields and White 2002).

The use of $\mathrm{CO}_{2}$ as an eco-friendly approach is one of the best options to control stored insect pests, because this approach has no harmful effects on stored food (Husain et al. 2017). This gas adversely affects the functions of normal body of beetles a including system of hormones, nervous system, digestive system, and circulatory system (Nicolas and Sillans 1989) because gas particles enter the insect body and open the spiracles permanently (Jay et al. 1971). Carbon dioxide can absorb and desorbed in grains without any chemical reaction and pose almost no effect on grains chemistry (Yamamoto et al. 1980). Management strategies to control all the developmental stages of pests through a modified atmosphere take several weeks because it depends upon the gas concentrations (Riudavets et al. 2009).

The $1^{\text {st }}$ objective of the research was to assess the required exposure time to get $100 \%$ mortality by exposing the adult stage of $S$. oryzae to $\mathrm{CO}_{2}$ at $27 \pm 2^{\circ} \mathrm{C}$ temperature and $65 \pm 5 \%$ relative humidity $(\mathrm{RH})$. The $2^{\text {nd }}$ objective of this research was to deliberate the notions and variations of MA, its impact on pests and on the superiority of the product being treated, the structure where it may be considered for use, and its compatibility in commercial settings.

\section{Materials and Methods}

\section{Rearing of homogenous insect culture}

The population of $S$. oryzae was collected from stored grains of the local grain market of district Multan. The collected population was reared under optimum laboratory conditions at $27 \pm 2{ }^{\circ} \mathrm{C}$ and $65 \%$ Relative humidity. Insect cultures were reared separately on two diets i.e., wheat and maize in sterilized ventilated plastic jars $(1 \mathrm{~L})$. Grains were also sterilized using an incubator at $50^{\circ} \mathrm{C}$ for 10 minutes to kill all living entities if present in grains. Moisture of grain was maintained at optimal conditions $\left(27 \pm 2^{\circ} \mathrm{C}\right.$ and $\left.65 \%\right)$ for rearing $S$. oryzae. From both cultures, hundred adult pairs were released in separate plastic jars with fresh diets for egg laying to produce a homogeneous $F_{1}$ generation. After 2-3 days, adults were sieved out and eggs were allowed behind on the diets for hatching. These larvae were provided optimum rearing conditions to pupate. Pupae of first day were collected in separate bottles on regular basis to obtain a homogenized population. Three days old adults of these homogenized populations were used for the experiment (Sarwar et al. 2020).

\section{Carbon dioxide $\left(\mathrm{CO}_{2}\right)$ source}

Carbon dioxide $\left(\mathrm{CO}_{2}\right)$ 99.9\% gas cylinder was obtained from medical gas supplier company, Faisalabad Punjab Pakistan.

\section{Gas purity analysis}

Biogas analyzer BIOGAS 5000 manufactured by "Geotech" was used to confirm the purity of $\mathrm{CO}_{2}$ gas.

\section{Gas application}

Sterilized transparent plastic bottles $(250 \mathrm{~mL})$ were used as exposure chambers. Each bottle was filled with $20 \mathrm{~g}$ sterilized respective diet to release 20 adult insects before injecting gas. Bottles were tightly plugged with special rubber septa. $\mathrm{CO}_{2}$ gas was applied by injection syringe. The injection syringe was connected to a three ways stopper to control the movement of gas, one side was connected to a short hose coming from gas cylinder, other was connected to the needle for injecting gas and third one was used to regulate the $\mathrm{CO}_{2}$ gas. A measured quantity of gas was injected into the exposure chamber after evacuating the same volume from exposure chamber through the injection plunger. Cylinder pressure was controlled by using pressure regulator gauges. After treatment bottles were kept undisturbed for definite periods inside the incubator at $27 \pm$ $2{ }^{\circ} \mathrm{C}$ and $65 \%$ R.H. Carbon dioxide modified atmospheres (MA) were labeled with 25 (T1), 30 (T2), 35 (T3), 40 (T4), 45 (T5) and 50\% (T6) $\mathrm{CO}_{2}$ by volume, respectively (Shekar et al. 2018).

\section{Data collection and analysis}

The experiment was maintained with four replications along with controlling under complete randomized design (CRD). Adult mortality data were collected at $24 \mathrm{~h}$ intervals up to complete mortality of treated insects. At the end of each exposure time, the bottles were opened, and insects were sieved out and transferred into $(9 \times 2.5 \mathrm{~cm})$ test tubes having fresh diet. Test tubes were closed with muslin cloth to prevent insect escape and placed in fresh air for up to 24 h. After $24 \mathrm{~h}$, dead insects were sieved out to calculate percent mortality in each treatment. If insects moved, they were considered as live (Annis and Morton 1997). 
Corrected percent mortality was calculated using Abbot's formula (Abbot 1925). Results were subjected to analysis of variance (ANOVA) using Statistix-8.1 software and LSD test was performed to compare the means at $5 \%$ significance level.

\section{Results}

Mortality effect of six modified atmospheres (MA) against $S$. oryzae adult on two diets

The overall mortality percent (\%) of $S$. oryzae was significantly $(P \leq 0.05)$ influenced by different concentrations of carbon dioxide modified atmospheres concerning time periods. The maximum mortality was recorded in T6 $(75.85 \%)$ followed by T5 $(72.79 \%)$, T4 $(62.92 \%), \mathrm{T} 3(49.38 \%), \mathrm{T} 2(39.22 \%)$ and $\mathrm{T} 1(27.48 \%)$, respectively. Diet also impacted the mortality rate as the maximum mortality\% was recorded in insects feeding on wheat $(64.89 \%)$ while the mortality in insects feeding on maize was $(44.32 \%)$ recorded. Maximum mortality was assessed after $120 \mathrm{~h}(88.32 \%)$ followed by $96 \mathrm{~h}(70.91 \%)$, $72 \mathrm{~h}(55.18 \%), 48 \mathrm{~h}(38.79 \%)$ and $24 \mathrm{~h}(25.82 \%)$ in all treatments. The interactions $(\mathrm{Ma} \times$ diet $)$ and (Diet $\times$ time $)$ were observed non-significant at $P \leq 0.05$. The two factors interaction $(\mathrm{Ma} \times$ time $)$ and three factors interaction $(\mathrm{Ma} \times$ diet $\times$ time) were recorded significant at $P \leq 0.05$ (Table 1).

The mortality $(\%)$ increased gradually from $\mathrm{T}_{1}$ to $\mathrm{T}_{6}$ and maximum mortality was observed in $\mathrm{T}_{6}$ from both diets. The mortality $\%$ was recorded high on wheat diet as compared to maize (Fig. 1).

In the same way, the interaction between MA $\times$ time also resulted in a significant increase in mortality $(\%)$. In all treatments, the mortality (\%) increased with the passage of time, and maximum mortality was recorded after $120 \mathrm{~h}$ (Fig. 2).

Interaction between three factors MA $\times$ diet $\times$ time positively increased the mortality (\%) among the treated adults of $S$. oryzae. The mortality (\%) was maximum in T6 and decreased gradually up to $\mathrm{T} 1$. In a comparison of diets, maximum mortality was recorded in the insects feeding on wheat diet in all treatments as compared to the insects feeding on maize diet (Fig. 3).

\section{Discussion}

Stored products and commodities have been focused to avoid insect pest infestation throughout the world by adopting chemical free strategies (Phillips and Throne 2010). Farmers depend upon the contact insecticide to control the harmful insects of stored commodities. These insecticides are disliked to use due to their hazardous and non-degradable effects on other organism (Morrison 2018). Fumigation is one of the most consistently used methods and several food stuffs are protected by using phosphine and methyl bromide but unluckily some stored product insects
Table 1: Impact of six different modified atmospheres and diets on percent mortality (\%) of $S$. Oryzae with respect to time (T1: 25\% $\mathrm{CO}_{2}$ ), (T2: $30 \% \mathrm{CO}_{2}$ ), (T3: $\left.35 \% \mathrm{CO}_{2}\right)$, (T4: $\left.40 \% \mathrm{CO}_{2}\right)$, (T5: $45 \% \mathrm{CO}_{2}$ ) and (T6: $\left.50 \% \mathrm{CO}_{2}\right)$

\begin{tabular}{ll}
\hline Factors & Mortality $(\%)$ \\
\cline { 1 - 2 } Modified atmosphere (MA) & $27.48 \mathrm{E}$ \\
$\mathrm{T}_{1}$ & $39.22 \mathrm{D}$ \\
$\mathrm{T}_{2}$ & $49.38 \mathrm{C}$ \\
$\mathrm{T}_{3}$ & $62.92 \mathrm{~B}$ \\
$\mathrm{~T}_{4}$ & $72.73 \mathrm{~A}$ \\
$\mathrm{~T}_{5}$ & $75.85 \mathrm{~A}$ \\
$\mathrm{~T}_{6}$ & \\
Diet $(\mathrm{Di})$ & $44.32 \mathrm{~B}$ \\
Maize & $64.89 \mathrm{~A}$ \\
Wheat & \\
Time (T) & $25.82 \mathrm{E}$ \\
24 & $38.79 \mathrm{D}$ \\
48 & $55.18 \mathrm{C}$ \\
72 & $70.91 \mathrm{~B}$ \\
96 & $82.32 \mathrm{~A}$ \\
120 & \\
LSD $(P \leq 0.05)$ & NS \\
Ma $\times$ diet $(P \leq 0.05)$ & $*$ \\
Ma $\times$ time $(P \leq 0.05)$ & NS \\
Diet $\times$ time $(P \leq 0.05)$ & $*$ \\
Ma $\times$ diet $\times$ time $(P \leq 0.05)$ & \\
Any two means within the column followed same letters are not significant at $P \leq$ \\
$0.05 * *$ significant, NS $=$ non-significant at $P \leq 0.05$
\end{tabular}

have gotten resistance against these chemicals (Wang et al. 2000). keeping in mind, the modified atmosphere is one of the best alternative method under a controlled atmosphere (Navarro 2006). $\mathrm{CO}_{2}$ be the best alternative replacement for phosphine and methyl bromide under stored conditions (Emami et al. 2016). The main benefit of this technique is that there is no harmful effect of the $\mathrm{CO}_{2}$ in the treated products. The level of oxygen can be maintained by vacuum or with the infusion of $\mathrm{CO}_{2}$ or other gases (Navarro 2006; Conyers and Bell 2007). Temperature significantly affects the mortality (\%) i.e., high temperature minimizes the exposure time to get $100 \%$ mortality while low temperature enhances the exposure period and also controls the efficacy of $\mathrm{CO}_{2}$ and other fumigants (Riudavets et al. 2009). Utilization of $\mathrm{CO}_{2}$ fumigation to limit the efficiency of harmful insects are generally productive for stored products (White and Jayas 2003; Pons et al. 2010). Our results indicated that the mortality\% increased with increase in $\mathrm{CO}_{2}$ concentration. The previous studies proved that the mortality increased with the enhancement of the modified atmosphere having 20, 40, 60 and $80 \% \mathrm{CO}_{2}$ concentration at $20^{\circ} \mathrm{C}$ used against Sitophilus spp. in maize grains and modified atmosphere comprising $75 \% \quad \mathrm{CO}_{2}$ has fruitful results against $S$. oryzae in different commodities (Carli et al. 2010). Insect pests cannot survive in an environment containing more than $35 \% \mathrm{CO}_{2}$ and less than $1 \%$ Oxygen level. Our results were in line with the findings of Carli et al. (2010) which revealed that mortality rate of exposed insects is enhanced with increased $\mathrm{CO}_{2}$ concentration on various diets. Annis and Morton (1997) also evaluated the efficacy of different concentrations viz., $15 \%$ to $100 \% \mathrm{CO}_{2}$ on the developmental stages of $S$. oryzae in wheat in which 


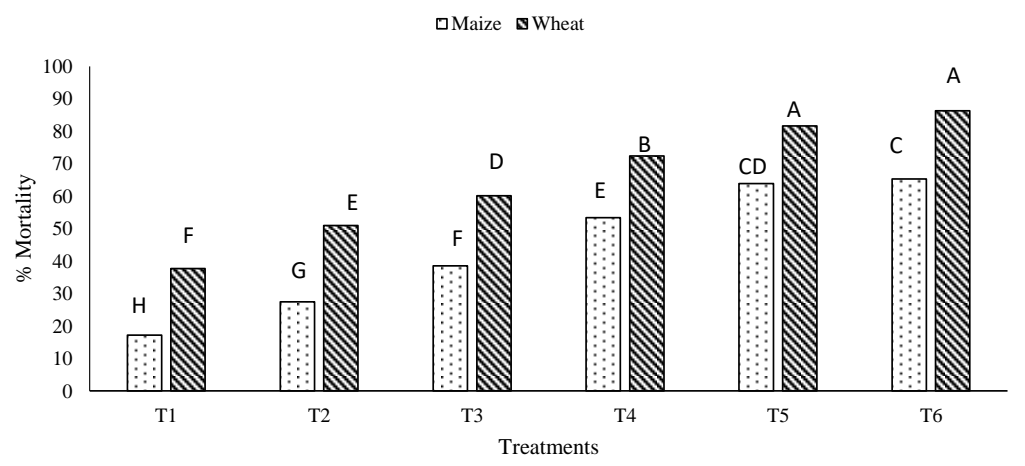

Fig. 1: Impact of interaction between modified atmosphere (MA) and diet on the percent (\%) mortality of $S$. Oryzae $\left(\mathrm{T} 1: 25 \% \mathrm{CO}_{2}\right),(\mathrm{T} 2$ : $\left.30 \% \mathrm{CO}_{2}\right),\left(\mathrm{T} 3: 35 \% \mathrm{CO}_{2}\right),\left(\mathrm{T} 4: 40 \% \mathrm{CO}_{2}\right),\left(\mathrm{T} 5: 45 \% \mathrm{CO}_{2}\right)$ and $\left(\mathrm{T} 6: 50 \% \mathrm{CO}_{2}\right)$

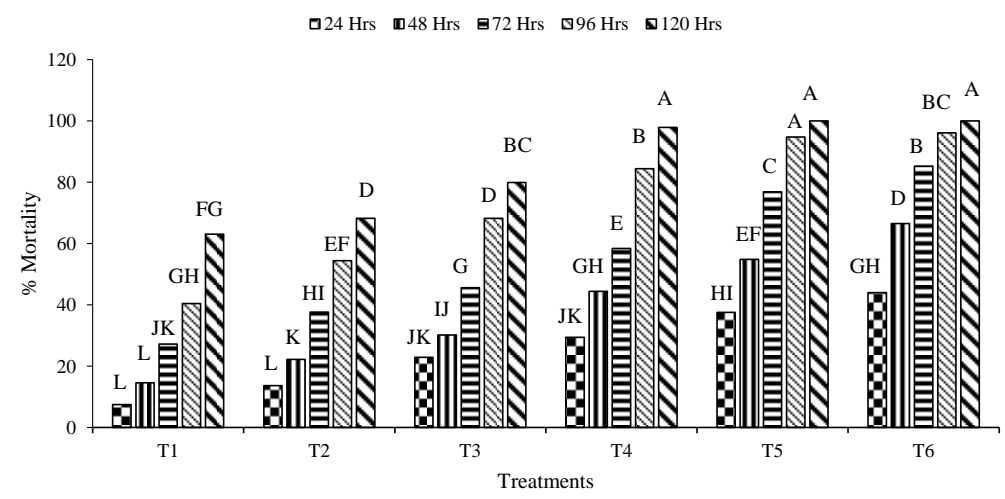

Fig. 2: Impact of interaction between modified atmosphere and time on percent mortality (\%) of S. oryzae $\left(\mathrm{T} 1: 25 \% \mathrm{CO}_{2}\right)$, ( $\mathrm{T}_{2}: 30 \%$ $\left.\mathrm{CO}_{2}\right),\left(\mathrm{T} 3: 35 \% \mathrm{CO}_{2}\right),\left(\mathrm{T} 4: 40 \% \mathrm{CO}_{2}\right),\left(\mathrm{T} 5: 45 \% \mathrm{CO}_{2}\right)$ and (T6: $\left.50 \% \mathrm{CO}_{2}\right)$

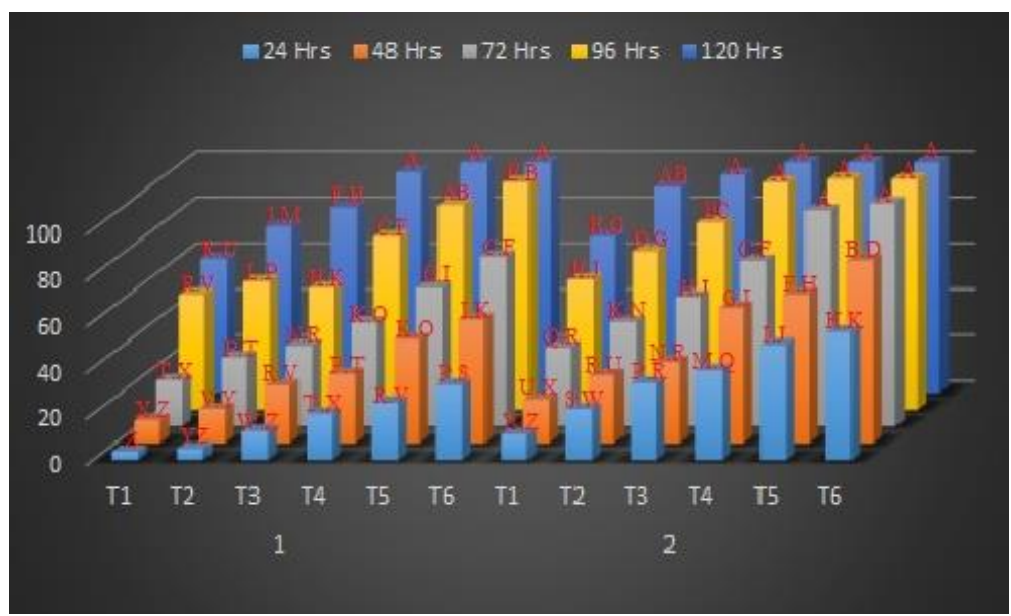

Fig. 3: Impact of interaction between modified atmosphere and diet with respect to time on mortality (\%) of $S$. oryzae $\left(\mathrm{T}_{1}: 25 \% \mathrm{CO}_{2}\right)$, (T2: $\left.30 \% \mathrm{CO}_{2}\right),\left(\mathrm{T} 3: 35 \% \mathrm{CO}_{2}\right),\left(\mathrm{T} 4: 40 \% \mathrm{CO}_{2}\right),\left(\mathrm{T} 5: 45 \% \mathrm{CO}_{2}\right)$ and $\left(\mathrm{T} 6: 50 \% \mathrm{CO}_{2}\right)$

the most tolerant stage was pupae while $100 \%$ mortality was obtained within 30 days in egg after exposure. The current work is also co-related with the findings of (Annis and Morton 1997) where death rate at adult stage increased with the enhancement of $\mathrm{CO}_{2}$ concentration which was followed by death rate at larval stage. Eggs of Tribolium confusum and Tribolium castaneum are not hatch able at $25 \% \mathrm{CO}_{2}$ atmosphere and high level of nitrogen and low level of oxygen had no effect on feasibility and incubation time, while the enhancement of $\mathrm{CO}_{2}$ concentration showed significant impact on the incubation period and feasibility (Ali and Lindgren 1970). Our result was also similar with 
(Ali and Lindgren 1970) finding which revealed that adult stage was more vulnerable followed by egg, larvae and pupae and in our result also showed that adult stage was more vulnerable than larvae.

Carbon dioxide concentrations have significant effect on mortality of $S$. oryzae. $\mathrm{CO}_{2}$ showed $56 \%$ mortality at $25 \%$ $\mathrm{CO}_{2}$ concentration after an exposure period of $120 \mathrm{~h}$ reared on maize diet while mortality was $100 \%$ at $50 \% \mathrm{CO}_{2}$ concentration under $50 \%$ concentration with in the same exposure time. Similarly, on wheat diet after an exposure period of $120 \mathrm{~h}$, mortality was $58 \%$ at $25 \% \quad \mathrm{CO}_{2}$ concentration while mortality was $100 \%$ at $45 \% \mathrm{CO}_{2}$ and $50 \% \mathrm{CO}_{2}$ concentrations within the same exposure time. Results showed that toxicity of different modified atmospheres increased by increasing $\mathrm{CO}_{2}$ gas concentration within same exposure periods. The similar findings were presented by Lindgren and Vincent (1970); Annis and Morton (1997) on two weevil species such as $S$. granarius and $S$. oryzae.

Results indicated that time and concentration posed significant effect on insect mortality reared on two different diets. Insect population reared on wheat diet was more susceptible as compared to maize diet that needs prolonged exposure time to achieve complete mortality. Similarly, increased concentrations decreased the exposure period and vice versa to achieve complete mortality. Present results showed that maximum mortality $\%$ was recorded in wheat as compared to maize but in previous study described that $T$. castaneum mortality \% increased with the increase of $\mathrm{CO}_{2}$ concentration and maximum mortality $\%$ was recorded in rice (Sarwar et al. 2021).

\section{Conclusion}

Our results indicated that maximum mortality of $S$. oryzae adult reared on wheat diet required a minimum of four days exposure period at $45 \% \mathrm{CO}_{2}$ concentration. Whereas, on maize diet, the exposure period of five days is required for maximum mortality at $45 \% \quad \mathrm{CO}_{2}$ concentration. It is indicated that maize diet induces vigor in reared insects as compared to wheat diet and increased the exposure time to achieve mortality of exposed insects. The outcomes affirmed that the utilization of high $\mathrm{CO}_{2}$ fixation in a gastight storehouse and airtight fixed huge sacks is a possible choice to control the event of occurrence during rice storage.

\section{Acknowledgements}

Not Applicable

\section{Author Contributions}

Zahid Mahmood Sarwar, Planned and supervised the research; Muhammad Mohsan, Zafar Hussain and Muhammad Shahbaz Asghar, conducted the research and wrote the manuscript. Adnan Badar proofread the manuscript and Muhammad Rafique Khan, helped in English editing and final formatting according to journal style.

\section{Conflicts of Interest}

All authors declare that they have no conflict of interest

\section{Data Availability}

Raw data and Materials are available

\section{Ethics Approval}

Not Applicable

\section{Funding Source}

Not Available of funds

\section{References}

Abbott WS (1925). A method of computing the effectiveness of an insecticide. J Econ Entomol 18:265-267

Adler C, HG Corinth, C Reichmuth (2000). Modified atmospheres. In: Alternatives to pesticides in stored-product IPM, pp:105-146. Springer, Boston, Massachusetts, USA

Ahmad H (1984). Storage of wheat in Pakistan. Progressive Farming, Pakistan

Ali NMT, DL Lindgren (1970). Egg hatch of Tribolium confusum (Coleoptera: Tenebrionidae) in different carbon dioxide and nitrogen atmospheres. Ann Entomol Soc Amer 63:1010-1012. https://doi.org/10.1093/aesa/63.4.1010

Alonso-Amelot ME, JL Avila-Núñez (2011). Comparison of seven methods for stored cereal losses to insects for their application in rural conditions. $J$ Stored Prod Res 47:82-87. https://doi.org/10.1016/j.jspr.2011.01.001

Annis P, R Morton (1997). The acute mortality effects of carbon dioxide on various life stages of Sitophilus oryzae. J Stored Prod Res 33:115124 https://doi.org/10.1016/S0022-474X(96)00050-1

Carli MD, B Bresolin, CPZ Noreña, I Lorini, A Brandelli (2010). Efficacy of modified atmosphere packaging to control Sitophilus spp. in organic maize grain. Braz Arch Biol Technol 53:1469-1476 https://doi.org/10.1590/S1516-89132010000600024

Conyers S, C Bell (2007). A novel use of modified atmospheres: Storage insect population control. J Stored Prod Res 43:367-374 https://doi.org/10.1016/j.jspr.2006.09.003

Emami K, O Valizadegan, S Aramideh (2016). Studies on respiratory toxicity of acetone and carbon dioxide on red flour beetle Tribolium castaneum (Herbst). Interaction 5:14-82

Emana G, A Tsedeke (1999). Management of maize stem borer using sowing date at Arsi-Negele. Pest Manage J Ethiopia 3:47-52

Fields PG, ND White (2002). Alternatives to methyl bromide treatments for stored-product and quarantine insects. Annu Rev Entomol 47:331359 https://doi.org/10.1146/annurev.ento.47.091201.145217

Haines C (1995). Grain storage in the tropics. In: Stored Grain Ecosystems, 55-100. Jays DS, NDG White, WE Munir (Eds.). Marcel Dekker, Incorporation

Husain M, S Sukirno, K Mehmood, M Tufail, KG Rasool, WS Alwaneen, AS Aldawood (2017). Effectiveness of carbon dioxide against different developmental stages of Cadra cautella and Tribolium castaneum. Environ Sci Pollut Res 24:12787-12795 DOI: $10.1007 / \mathrm{s} 11356-017-8860-5$

Isman MB (2006). Botanical insecticides, deterrents, and repellents in modern agriculture and an increasingly regulated world. Anпи Rev Entomol 51:45-66 DOI: 10.1146/annurev.ento.51.110104.151146 
Jay EG, RT Arbogast, GC Pearman Jr (1971). Relative humidity: Its importance in the control of stored-product insects with modified atmospheric gas concentrations. J Stored Prod Res 6:325-329 https://doi.org/10.1016/0022-474X(71)90045-2

Kennett DJ, KM Prufer, BJ Culleton, RJ George, M Robinson, WR Trask, GM Buckley, E Moes, EJ Kate, TK Harper, L'O Donnell, EE Ray, EC Hill, A Alsgaard, C Merriman, C Meredith, HJH Edgar, JJ Awe, SM Gutierrez (2020). Early isotopic evidence for maize as a staple grain in the Americas. Sci Adv 6:1-12 https://doi.org/10.1126/sciadv.aba3245

Khan FA (2018). The design, fabrication and performance evaluation of solar sustained batch type maize dryer for value addition. Intl J Agric Environ Food Sci 2:50-56 DOI:10.31015/jaefs. 18008

Lindgren D, L Vincent (1970). Effect of atmospheric gases alone or in combination on the mortality of granary and rice weevils. $J$ Econ Entomol 63:1926-1929 https://doi.org/10.1093/jee/63.6.1926

Morrison AM (2018). Marketing and managing tourism destinations

Navarro S (2006). Modified atmospheres for the control of stored-product insects and mites. In: Insect management for food storage and processing, pp: 105-146 DOI:10.1016/B978-1-891127-46-5.500167

Nicolas G, D Sillans (1989). Immediate and latent effects of carbon dioxide on insects. Annu Rev Entomol 34:97-116 https://doi.org/10.1146/annurev.en.34.010189.000525

Padmasri A, C Srinivas, KV Lakshmi, T Pradeep, K Rameash, C Anuradha, B Anil (2017). Management of rice weevil (Sitophilus oryzae L.) in maize by botanical seed treatments. Intl J Curr Microbiol Appl Sci 6:3543-3555 https://doi.org/10.20546/ijcmas.2017.612.412

Pathak K, A Jha (2003). Survey of insect pests of stored maize and paddy in north eastern region. Ind J Entomol 65:127-133

Phillips TW, JE Throne (2010). Biorational approaches to managing storedproduct insects. Annu Rev Entomol 55:375-397. DOI: 10.1146/annurev.ento.54.110807.090451

Pons M, A Camara, S Guri, J Riudavets (2010). The use of carbon dioxide in big bags and containers for the control of pest in food products. In: $10^{\text {th }}$ International Working Conference on Stored Product Protection, 414-418 DOI:10.5073/jka.2010.425.142
Riudavets J, C Castañé, O Alomar, MJ Pons, R Gabarra (2009). Modified atmosphere packaging (MAP) as an alternative measure for controlling ten pests that attack processed food products. $J$ Stored Prod Res 45:91-96 https://doi.org/10.1016/j.jspr.2008.10.001

Shekar RV, BA Kumar, A Padmasri, M Shanti (2018). Mortality of Sitophilus oryzae in modified atmosphere with elevated levels of $\mathrm{CO}_{2}$. J Pharmacogn Phytochem 7:1240-1245

Sarwar ZM, N Fatima, M Sajjad (2021). Mortality effects of hypercapnia in modified atmospheres on larval and adult stages of red flour beetle Tribolium castaneum (Herbst). Intl J Trop Ins Sci 41:587-592 https://doi.org/10.1007/s42690-020-00243-3

Sarwar ZM, N Fatima, M Sajjad (2020). Mortality effects of hypercapnia in modified atmospheres on larval and adult stages of red flour beetle Tribolium castaneum (Herbst). Intl J Trop Ins Sci 41:587-592 https://doi.org/10.1007/s42690-020-00243-3

Wallbank BE, PJ Collins (2003). Recent changes in resistance to grain protectants in eastern Australia. In: Proceedings of the Australian Postharvest Technical Conference "Stored Grain in Australia", pp:66-70. Wright EJ, MC Webb, E Highley (Eds). Canberra, Australia

Wang JJ, ZM Zhao, JH Tsai (2000). Resistance and some enzyme activities in Liposcelis bostrychophila Badonnel (Psocoptera: Liposcelididae) in relation to carbon dioxide enriched atmospheres. J Stored Prod Res 36:297-308 DOI: 10.1016/s0022-474x(99)00051-x

Weaver DK, AR Petroff (2005). Introduction stored grain pest management.In: Pest Management for Grain Storage and Fumigation, pp:102-116. USDA-ARS and the University of Wisconsin

White ND, DS Jayas (2003). Controlled atmosphere storage of grain. Handbook of postharvest technology, pp:235-251. Cereals Fruits Vegetables Tea Spices

Yamamoto A, H Mitsuda, J Shejbal (1980). Characteristics of Carbon Dioxide Gas Adsorption by Grain and its Components, p:247. Elsevier, Amsterdam

Yu H, B Li, D Shen, J Cao, B Mao (2017). Study on prediction model of grain post-harvest loss. Proc Comput Sci 122:122-129 DOI:10.1016/j.procs.2017.11.350 